\title{
miR-214 mediates vascular inflammation and apoptosis via PTEN expression
}

\author{
MINGLIANG WANG, MIN LIU, TING NI and QILIANG LIU \\ Department of Cardiology, Shanghai Putuo District People's Hospital, Shanghai 200060, P.R. China
}

Received March 16, 2017; Accepted September 1, 2017

DOI: $10.3892 / \mathrm{mmr} .2018 .9185$

\begin{abstract}
The present study aimed to investigate the role of miR-214 on inflammation and apoptosis in the vascular system and to examine its potential mechanisms. Anti-miR-214 mimics were used to downregulate miR-214 expression in HUVECs. Cell viability and the apoptosis rate were measured using MTT assay and flow cytometry. Tumor necrosis factor (TNF)- $\alpha$, interleukin (IL)-1 $\beta$, IL-6 and IL-18 levels were measured using ELISA kits. Following this, caspase-3/9, Bax, phosphatase and tensin homolog (PTEN), nuclear factor (NF)- $\kappa \mathrm{B}$ and phosphorylated-(p)-protein kinase $\mathrm{B}$ (Akt) protein expression were analyzed using western blotting. The results demonstrated that anti-miR-214 mimics inhibited cell proliferation, increased apoptosis and inflammatory factors (TNF- $\alpha$, IL-1 $\beta$, IL- 6 and IL-18 levels), inhibited cell proliferation, and induced Bax protein expression in TNF- $\alpha$-induced vascular endothelial cells through induction of PTEN and NF- $\kappa$ B protein expression and inhibition of Akt protein expression. The PTEN inhibitor inhibited the function of anti-miR-214 on apoptosis and inflammation in TNF- $\alpha$-induced inflammation vascular endothelial cells through the PTEN/Akt signaling pathway. These results suggest that miR-214 mediates vascular inflammation and apoptosis via PTEN expression.
\end{abstract}

\section{Introduction}

According to the World Health Organization (WHO), cardiovascular disease has become one of the most dangerous diseases endangering human health. It is predicted that cardiovascular diseases will progress to become the leading cause of human mortality by 2020 , thus is an important public health problem (1). There are 230 million people with cardiovascular disease in China and there are $\sim 3$ million cases of cardiovascular disease-associated mortality per year, accounting for

Correspondence to: Dr Mingliang Wang, Department of Cardiology, Shanghai Putuo District People's Hospital, 1291 Jiangning Road, Shanghai 200060, P.R. China

E-mail:wqjq069743@126.com

Key words: microRNA-214, vascular system, inflammation, apoptosis, phosphatase and tensin homolog $\sim 50 \%$ of all causes of mortality in China (2). Someone dies due to cardiovascular complications every $13 \mathrm{sec}$ (2) and it is predicted that by 2030 , the morbidity and mortality of cardiovascular disease in China will increase by $73 \%$ (2). At present, cardiovascular disease costs up to 300 billion yuan ( $£ 35$ billion) in China every year, in addition its growth rate is almost twice that of China's GDP, thus will cause a large economic burden on society (2). Atherosclerosis (AS) accounts for the largest proportion of cardiovascular disease, along with the highest morbidity and mortality (3). Chronic vascular inflammatory reaction serves a significant role in the occurrence and development of AS (4). In addition, vascular inflammatory injury is an important pathogenic mechanism leading to the occurrence and development of hypertension, aneurysm, in addition to percutaneous transluminal coronary angioplasty (5). Previous studies have demonstrated that tumor necrosis factor (TNF)- $\alpha$-induced inflammation in vascular endothelial cells is a common model for studying vascular inflammation (5).

MicroRNAs (miRNAs) are small non-coding RNAs that are approximately 19-22 bases in length. They function normally as regulators of gene expression, and have been demonstrated to serve key regulatory roles in biological processes (6). This regulation is also present in the self-renewal of stem cells and the differentiation of a variety of cell lineages (7). It is confirmed that the generation of miRNAs can interfere with the process of angiogenesis and the function of vascular endothelial cells (8).

Inflammation is a common cause of endothelial dysfunction. Under physiological conditions, the endothelium will affect the vascular inflammation through the release of nitric oxide (9). However, endothelial dysfunction will produce excessive reactive oxygen species and aggravate inflammation of the blood vessels, thereby damaging the blood vessels (10). Various inflammatory factors are associated with endothelial dysfunction and atherosclerosis (11). Inflammation is also associated with overexpression of TNF- $\alpha$ and interleukin (IL)-6, which promotes the adhesion and migration of monocytes (12). In addition, these inflammatory factors can also cause expression of adhesion molecules, including vascular cell adhesion molecules, intracellular adhesion molecules and monocyte chemotactic factor 1 in endothelial cells and monocytes. Thus, this causes more severe endothelial dysfunction. Upon reaching the intima, the monocytes are transformed into giant cells, which are conductive to the expression of 
receptors that facilitate lipid uptake and accumulation (12). In this way, the macrophages can be transformed into foam cells. Subsequently, smooth muscle cell migration occurs, which together with foam cells, form necrotic nuclei, leading to the formation of atherosclerotic plaques (13). Therefore, the endothelial dysfunction caused by inflammation additionally has a direct association with the occurrence and development of vascular diseases.

A previous study identified that PTEN is closely associated with tumor angiogenesis (14). It can inhibit the angiogenesis by activating the phosphoinositide 3-kinase (PI3K) signaling pathway and regulating hypoxia-inducible factor 1 in addition to vascular endothelial growth factor (15). The present study aimed to investigate the role of miRNA (miR)-214 on inflammation and apoptosis in the vascular system and to examine its potential mechanism.

\section{Materials and methods}

Cell culture and transfection. Human umbilical vein endothelial cells (HUVECs) were obtained from the Shanghai Cell Bank of Chinese Academy of Sciences (Shanghai, China) and cultured in M199 medium (Hyclone; GE Healthcare Life Sciences, Logan, UT, USA) containing 10\% fetal bovine serum (Hyclone; GE Healthcare Life Sciences) at $37^{\circ} \mathrm{C}$ in a humidified 5\% $\mathrm{CO}_{2}$ environment. Anti-miR-214 mimics were obtained from Shanghai Sangon Biotech Co., Ltd. (Shanghai, China). Anti-miR-214 mimics were transfected with Lipofectamine ${ }^{\circledR} 2000$ Reagent (Invitrogen; Thermo Fisher Scientific, Inc., Waltham, MA, USA) into the HUVECs. After transfection at $48 \mathrm{~h}$, HUVECs were induced by $500 \mathrm{ng} / \mathrm{ml}$ TNF- $\alpha$ (cat. no. sc-4564; Santa Cruz Biotechnology, Inc., Dallas, TX, USA) for $24 \mathrm{~h}$.

Reverse transcription-polymerase chain reaction (RT-PCR). Total RNA isolation was conducted using TRIzol (Invitrogen; Thermo Fisher Scientific, Inc.). A total of $1 \mu \mathrm{g}$ total RNA was reverse transcribed into cDNA using the PrimeScript ${ }^{\mathrm{TM}}$ RT reagent kit (Takara Bio, Inc., Otsu, Japan) according to the manufacturer's protocol. The RT-PCR reaction was conducted using an AB7300 thermal cycler (Applied Biosystems; Thermo Fisher Scientific, Inc.) using Platinum SYBR Green qPCR SuperMix-UDG (Invitrogen; Thermo Fisher Scientific, Inc.). The primers used were as follows: miR-214, forward 5'-CAC CGCATCCGCTCACCTGTACAGC-3' and reverse 5'-AAA CGCTGTACAGGTGAGCGGATGC-3'; U6, forward 5'-CTC GCTTCGGCAGCACA-3' and reverse 5'-AACGCTTCACGA ATTTGCGT-3'. The amplification conditions were as follows: Initial denaturation at $95^{\circ} \mathrm{C}$ for $10 \mathrm{~min}$, followed by 40 cycles for $30 \mathrm{sec}$ at $95^{\circ} \mathrm{C}$ and $1 \mathrm{~min}$ in $60^{\circ} \mathrm{C}$. Data were analyzed using the $2^{-\Delta \Delta \mathrm{Cq}}$ method (16).

Cell proliferation. Cell viability was determined by the MTT [3-(4,5-dimethylthiazol-2-yl)-2,5-diphenyl tetrazolium bromide] assay. MTT was added $(5.0 \mathrm{mg} / \mathrm{ml})$ into a plate and incubated at $37^{\circ} \mathrm{C}$ in $5 \% \mathrm{CO}_{2}$ for $4 \mathrm{~h}$. Dimethyl sulfoxide was added to each well and shaken for $20 \mathrm{~min}$ at $37^{\circ} \mathrm{C}$. The optical density was determined (Stat Fax 2100 Microplate Reader; Awareness Technology, Inc., Palm City, FL, USA) at $490 \mathrm{~nm}$.
Apoptosis assay. Cells were then washed with PBS and pelleted by centrifugation at $500 \mathrm{x}$ g for $5 \mathrm{~min}$ at $4^{\circ} \mathrm{C}$ and resuspended in binding buffer (FACS Vantage Buffer; BD Biosciences, San Jose, CA, USA). Cells were stained with $5 \mu \mathrm{g}$ Annexin-V-fluorescein isothiocyanate and $5 \mu \mathrm{g}$ propidium iodide at room temperature in the dark for $15 \mathrm{~min}$. The samples were examined by flow cytometry (FACS Vantage; BD Biosciences).

ELISA. Cells were harvested by scraping from the wells, proteins were obtained with radioimmunoprecipitation assay lysis buffer (RIPA; Bio-Rad Laboratories, Inc., Hercules, CA, USA). The protein concentrations were determined using Coomassie protein reagent (Bio-Rad Laboratories, Inc.). Proteins $(5 \mu \mathrm{g})$ were used to measure TNF- $\alpha$, IL- $1 \beta$, IL- 6 and IL-18 levels using ELISA kits. The optical density was determined (Stat Fax 2100 Microplate Reader) at $450 \mathrm{~nm}$. Caspase-3 and caspase- 9 activity were measured using Caspase- 3 and caspase-9 activity kits (Beyotime Institute of Biotechnology, Jiangsu, China). The optical density was determined (Stat Fax 2100 Microplate Reader) at $405 \mathrm{~nm}$.

Western blotting. Cells were harvested by scraping from the wells, proteins were obtained with RIPA. The protein concentrations were determined using Coomassie protein reagent. Protein $(50 \mu \mathrm{g})$ was loaded per lane and separated by $8-10 \%$ SDS-PAGE and then transferred to nitrocellulose membranes (GE Healthcare Life Sciences, Arlington Heights, IL, USA). Membranes were blocked in Tris-buffered saline containing $0.1 \%$ Tween-20 and 5\% skimmed milk for $1 \mathrm{~h}$ at $37^{\circ} \mathrm{C}$ and incubated with primary antibodies: Bax (cat. no. sc-6236; 1:1,000; Santa Cruz Biotechnology, Inc.), PTEN (cat. no. sc-9145; 1:1,000; Santa Cruz Biotechnology, Inc.), NF-кB (cat. no. sc-109; 1:2,000; Santa Cruz Biotechnology, Inc.), p-Akt (cat. no. sc-7985-R; 1:500; Santa Cruz Biotechnology, Inc.) and GAPDH (cat. no. sc-25778; 1:5,000; Santa Cruz Biotechnology, Inc.) at $4{ }^{\circ} \mathrm{C}$ overnight, followed by incubation with anti-rabbit IgG peroxidase-conjugated secondary antibodies (cat. no. 7054; 1:5,000; Cell Signaling Technology, Inc., Danvers, MA, USA) for $1 \mathrm{~h}$ at $37^{\circ} \mathrm{C}$. The detection of specific proteins was carried out with an ECL Western blotting and quantified using a G: Box gel imaging system by Syngene (Syngene, Frederick, MD, USA).

Statistical analysis. Data are expressed as the mean \pm standard deviation. Statistical analysis of data was performed using one-way analysis of variance. $\mathrm{P}<0.05$ was considered to indicate a statistically significant difference.

\section{Results}

Cell proliferation and cell apoptosis in vascular endothelial cells with miR-214 downregulation. In order to explore the role of miR-214 on cell growth and apoptosis in TNF- $\alpha$-induced inflammation in vascular endothelial cells, the cell proliferation and cell apoptosis were analyzed. As presented in Fig. 1A, anti-miR-214 mimics reduced miR-214 expression in vascular endothelial cells induced by TNF- $\alpha$, compared with the control group. However, miR-214 downregulation inhibited cell proliferation and induced apoptosis of TNF- $\alpha$-induced 
A

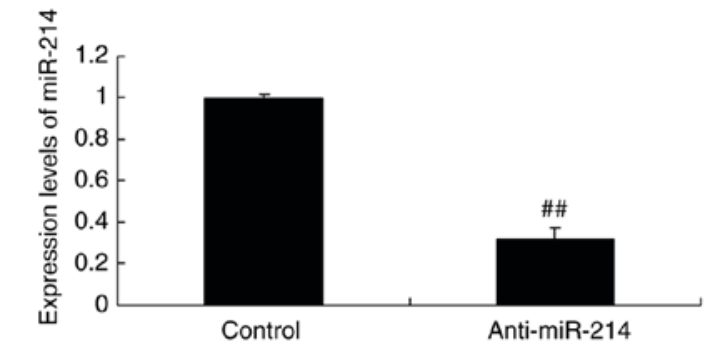

C

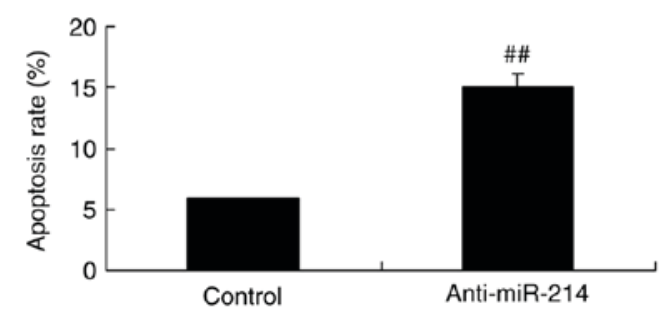

B

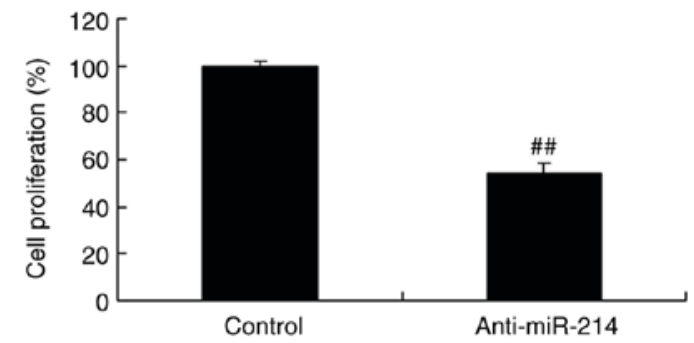

\section{$\mathrm{D}$}

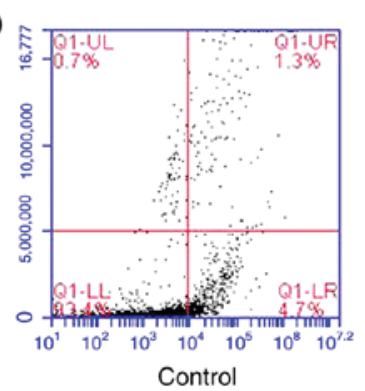

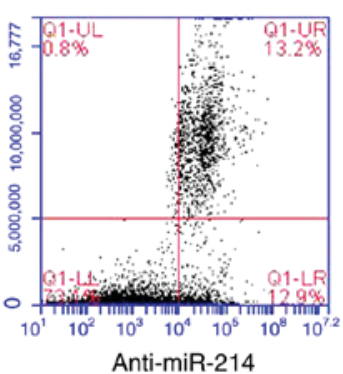

Figure 1. Cell proliferation and cell apoptosis in vascular endothelial cells by miR-214 downregulation. (A) miR-214 expression, (B) cell proliferation and (C and D) cell apoptosis in vascular endothelial cells by miR-214 downregulation. ${ }^{\# \#} \mathrm{P}<0.01$ vs. control group. miR, microRNA; control, control group; anti-miR-214, anti-miR-214 mimics group.
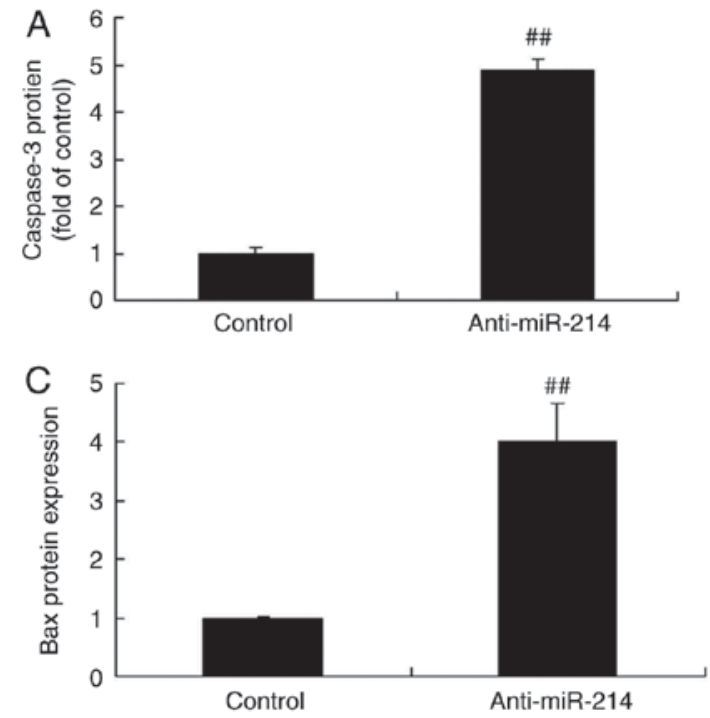

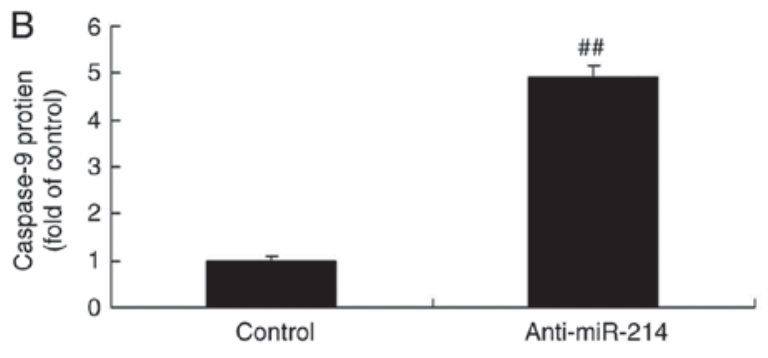

D

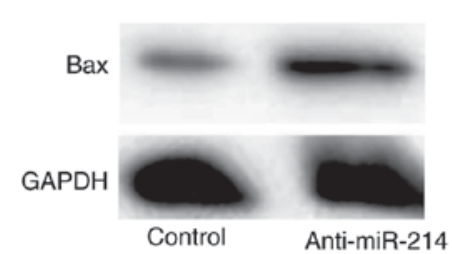

Figure 2. Caspase-3/9 activity and Bax protein expression in vascular endothelial cells by miR-214 downregulation. (A) Caspase-3 and (B) caspase-9 activity levels were determined. (C) Bax protein expression was quantified and measured by (D) western blotting in vascular endothelial cells by miR-214 downregulation. ${ }^{\# \#} \mathrm{P}<0.01$ vs. control group. miR, microRNA; control, control group; anti-miR-214, anti-miR-214 mimics group.

inflammation vascular endothelial cells, compared with the control group (Fig. 1B-D).

Caspase-3/9 and Bax protein expression in vascular endothelial cells with miR-214 downregulation. Subsequently, the function of miR-214 in apoptosis in TNF- $\alpha$-induced inflammation in vascular endothelial cells was investigated, with caspase-3/9 activity and Bax protein expression as markers of apoptosis. There were significant increases of caspase-3/9 activity and Bax protein expression in TNF- $\alpha$-induced inflammation in vascular endothelial cells with miR-214 downregulation, which indicated that miR-214 downregulation induced vascular endothelial cell apoptosis (Fig. 2).
Inflammation changes in vascular endothelial cells with miR-214 downregulation. To determine the function of anti-miR-214 on inflammation changes in vascular endothelial cells, TNF- $\alpha$, IL-1 $\beta$, IL-6 and IL-18 levels were determined using ELISA kits. Following transfection with miR-214 mimics for $48 \mathrm{~h}$, TNF- $\alpha$, IL-1 $\beta$, IL- 6 and IL-18 levels were significantly increased in TNF- $\alpha$-induced inflammation in vascular endothelial cells with miR-214 down-expression (Fig. 3).

PTEN and NF- $\kappa B$ protein expression in vascular endothelial cells with miR-214 downregulation. In order to examine the mechanism of anti-miR-214 on inflammation and apoptosis 
A

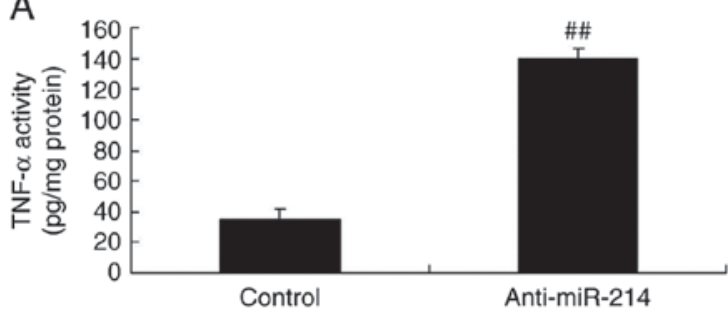

C

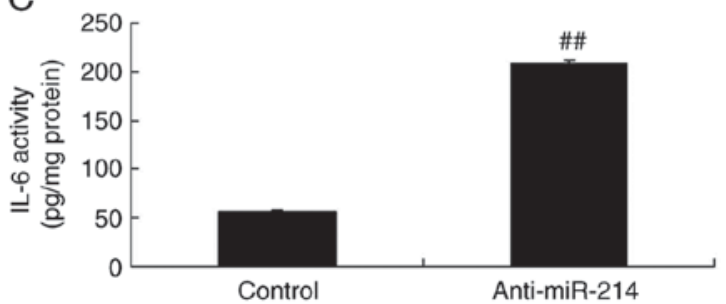

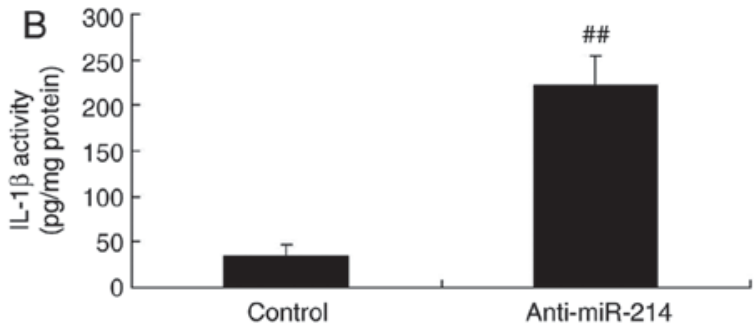

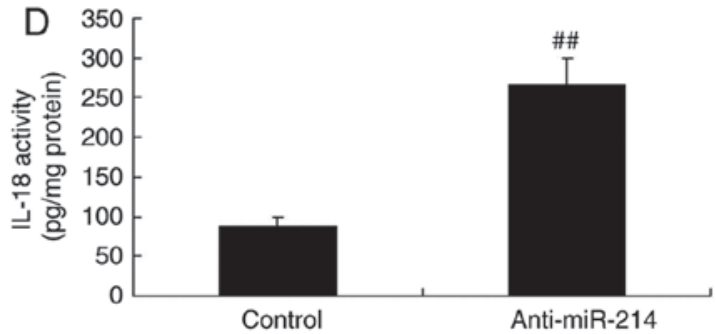

Figure 3. Inflammatory changes in vascular endothelial cells by miR-214 downregulation. (A) TNF- $\alpha$, (B) IL-1 $\beta$, (C) IL-6 and (D) IL-18 activity levels are presented. ${ }^{\#} \mathrm{P}<0.01$ vs. control group. MiR, microRNA; TNF- $\alpha$, tumor necrosis factor $\alpha$; IL, interleukin; control, control group; anti-miR-214, anti-miR-214 mimics group.
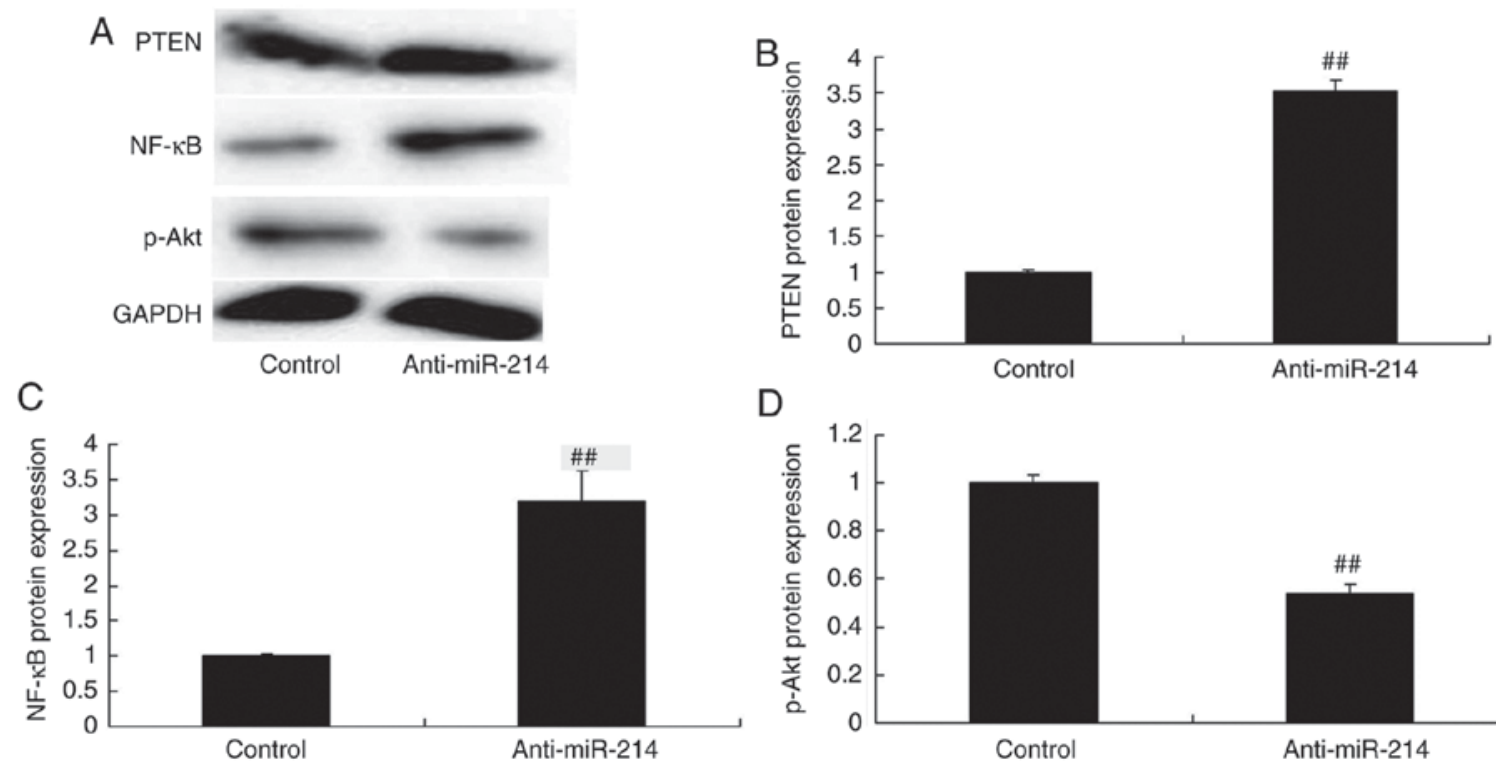

D

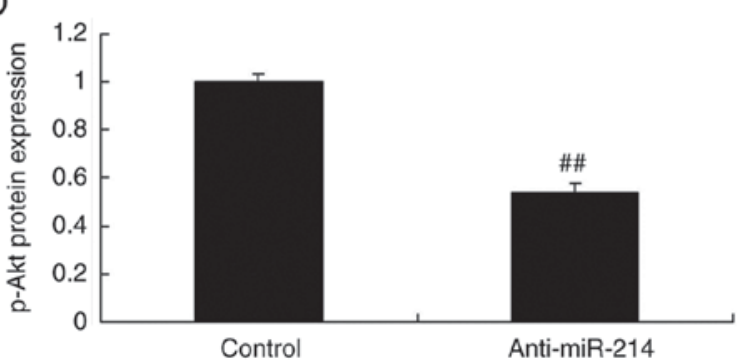

Figure 4. PTEN and NF- $\kappa$ B protein expression in vascular endothelial cells by miR-214 downregulation. (A) Western blotting of PTEN, NF- $\mathrm{B}$ and p-Akt protein expression and statistical analysis of (B) PTEN, (C) NF- $\mathrm{kB}$ and (D) p-Akt in vascular endothelial cells by miR-214 downregulation. ${ }^{\# \#} \mathrm{P}<0.01 \mathrm{vs}$. control group. PTEN, phosphatase and tensin homolog; NF- $\mathrm{B}$, nuclear factor $\kappa \mathrm{B}$; miR, microRNA; p-Akt, phosphorylated protein kinase B; control, control group; anti-miR-214, anti-miR-214 mimics group.

in TNF- $\alpha$-induced inflammation in vascular endothelial cells, PTEN and $\mathrm{NF}-\kappa \mathrm{B}$ protein expression levels were measured in vascular endothelial cells. Fig. 4 indicates that PTEN and $\mathrm{NF}-\kappa \mathrm{B}$ protein expression were significantly induced, and $\mathrm{p}$-Akt protein expression was significantly reduced in TNF- $\alpha$-induced inflammation in vascular endothelial cells by miR-214 downregulation.

PTEN inhibitor inhibited the function of miR-214 on PTEN and $N F-\kappa B$ protein expression in vascular endothelial cells. According to the above results, the PTEN inhibitor was used to adjust PTEN expression in TNF- $\alpha$-induced inflammation in vascular endothelial cells by miR-214 downregulation. As presented in Fig. 5, the PTEN inhibitor could inhibit PTEN and $\mathrm{NF}-\kappa \mathrm{B}$ protein expression, and induced $\mathrm{p}-\mathrm{Akt}$ protein expression in $\mathrm{TNF}-\alpha$-induced inflammation in vascular endothelial cells by miR-214 downregulation.

PTEN inhibitor inhibited the function of anti-miR-214 on apoptosis in vascular endothelial cells. Subsequently, it was investigated whether the PTEN inhibitor decreased the function of miR-214 on apoptosis in vascular endothelial cells. The inhibition of PTEN expression promoted cell proliferation and inhibited apoptosis of TNF- $\alpha$-induced inflammation in vascular endothelial cells by miR-214 downregulation (Fig. 6). 

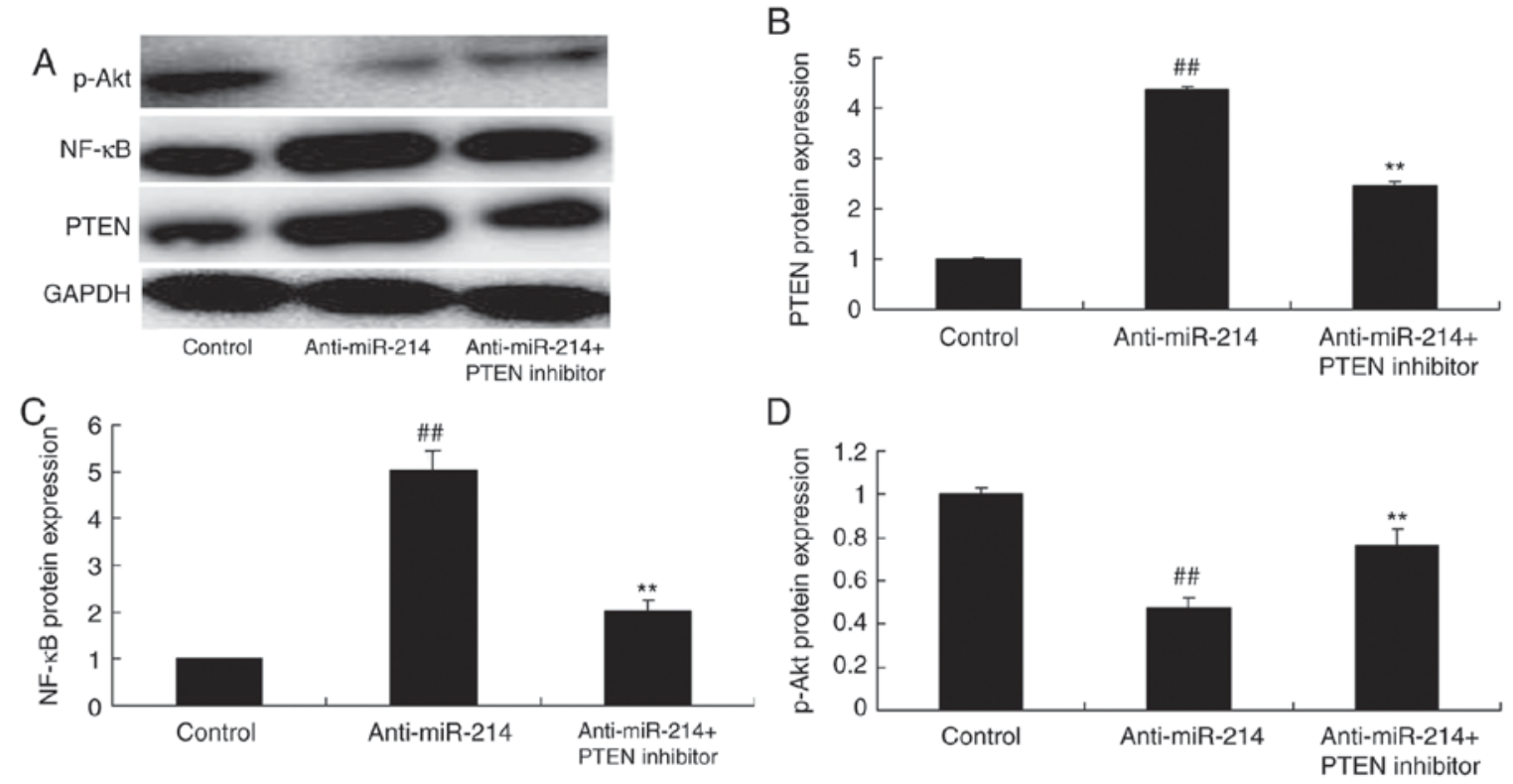

Figure 5. PTEN inhibitor, inhibited the function of miR-214 on PTEN and NF- $\mathrm{B}$ protein expression in vascular endothelial cells. the PTEN inhibitor inhibited the function of miR-214 on PTEN, NF-kB and p-Akt protein expression observed by (A) western blotting and statistical analysis of (B) PTEN, (C) NF-kB and (D) p-Akt in vascular endothelial cells by miR-214 downregulation. ${ }^{\# \#} \mathrm{P}<0.01$ vs. control group ${ }^{* * *} \mathrm{P}<0.01 \mathrm{vs}$. anti-miR-214 mimics group. PTEN, phosphatase and tensin homolog; miR, microRNA; PTEN inhibitor, VO-Ohpic trihydrate + anti-miR-214 group; NF- $\kappa \mathrm{B}$, nuclear factor $\kappa \mathrm{B}$; p-Akt, phosphorylated protein kinase B; control, control group; Aanti-miR-214, anti-miR-214 mimics group.

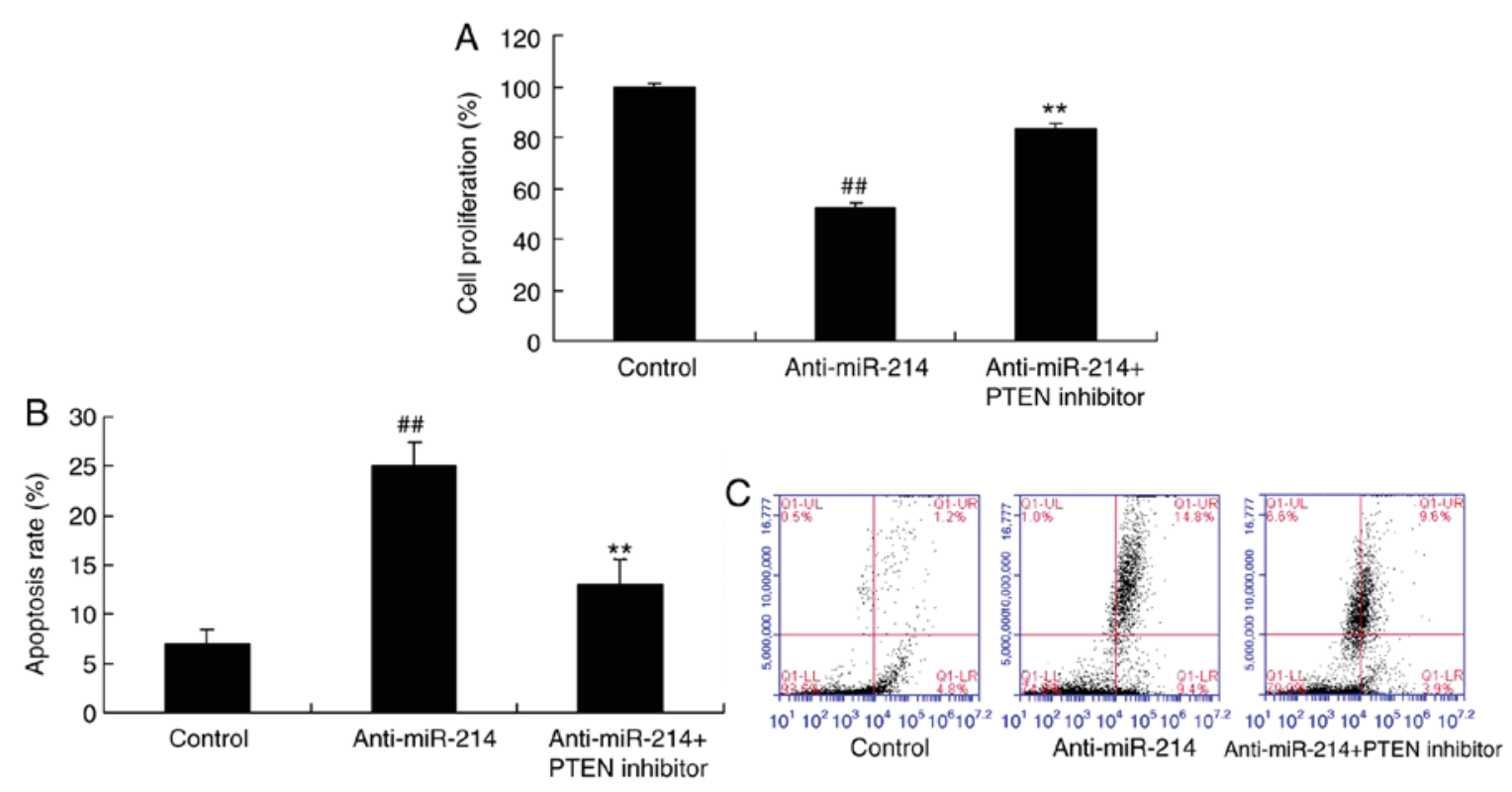

Figure 6. PTEN inhibitor, inhibited the function of anti-miR-214 on apoptosis in vascular endothelial cells. The PTEN inhibitor inhibited the function of anti-miR-214 on (A) cell proliferation and (B and C) cell apoptosis in vascular endothelial cells by miR-214 downregulation. ${ }^{\# \#} \mathrm{P}<0.01$ vs. control group, ${ }^{* *} \mathrm{P}<0.01$ vs. anti-miR-214 mimics group. PTEN, phosphatase and tensin homolog; miR, microRNA; PTEN inhibitor, VO-Ohpic trihydrate + anti-miR-214 group; control, control group; anti-miR-214, anti-miR-214 mimics group.

PTEN inhibitor inhibited the function of miR-214 on caspase-3 and Bax protein expression in vascular endothelial cells. In addition, it was identified that the inhibition of PTEN expression decreased the function of miR-214 on caspase-3 and Bax protein expression in vascular endothelial cells (Fig. 7).

PTEN inhibitor inhibited the function of miR-214 on inflammation in vascular endothelial cells. To investigate the role of anti-miR-214 on inflammation in vascular endothelial cells, TNF- $\alpha$, IL-1 $\beta$, IL- 6 and IL-18 levels were measured. The inhibition of PTEN expression significantly reduced TNF- $\alpha$, IL-1 $\beta$, IL- 6 and IL-18 levels in TNF- $\alpha$-induced inflammation in vascular endothelial cells by miR-214 downregulation (Fig. 8).

\section{Discussion}

A clinical epidemiological survey has indicated that the morbidity and mortality of cardiovascular disease in China 

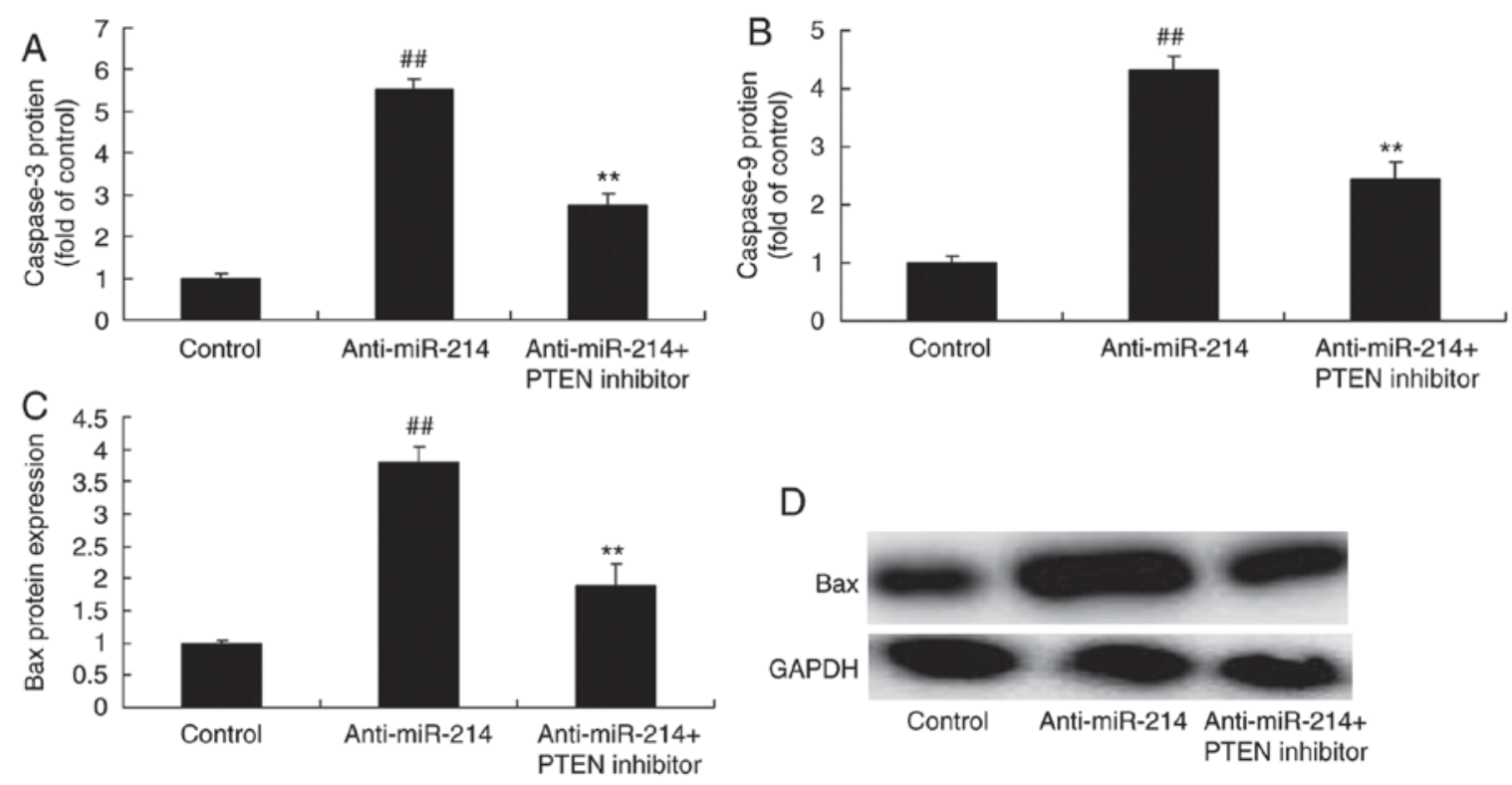

Figure 7. PTEN inhibitor, inhibited the function of miR-214 on caspase-3/9 and Bax protein expression in vascular endothelial cells. The PTEN inhibitor inhibited the function of miR-214 on (A) caspase-3 and (B) caspase-9 activity levels. (C) Bax protein expression revealed by (D) western blotting in vascular endothelial cells by miR-214 downregulation. ${ }^{\# \#} \mathrm{P}<0.01$ vs. control group, ${ }^{* *} \mathrm{P}<0.01$ vs. anti-miR-214 mimics group. PTEN, phosphatase and tensin homolog; miR, microRNA; PTEN inhibitor, VO-Ohpic trihydrate + anti-miR-214 group; control, control group; anti-miR-214, anti-miR-214 mimics group.
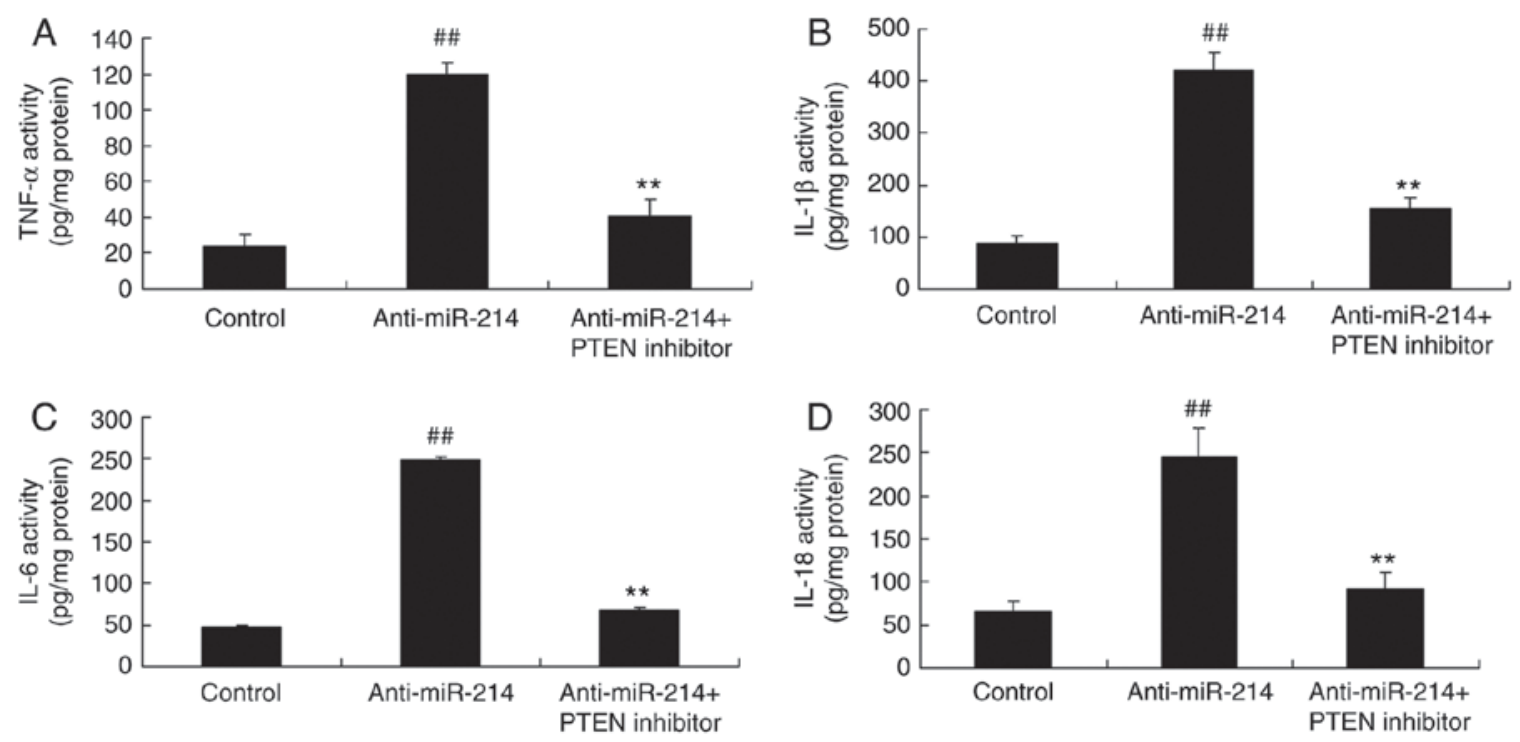

Figure 8. PTEN inhibitor, inhibited the function of miR-214 on inflammation in vascular endothelial cells. The PTEN inhibitor inhibited the function of miR-214 on (A) TNF- $\alpha$, (B) IL-1 $\beta$, (C) IL-6 and (D) IL-18 levels. ${ }^{* \#} \mathrm{P}<0.01$ vs. control group, ${ }^{* *} \mathrm{P}<0.01$ vs. anti-miR-214 mimics group. PTEN, phosphatase and tensin homolog; miR, microRNA; PTEN inhibitor, VO-Ohpic trihydrate + anti-miR-214 group; TNF- $\alpha$, tumor necrosis factor $\alpha$; IL, interleukin; control, control group; anti-miR-214, anti-miR-214 mimics group.

is increasing, it is predicted that the cases of cardiovascular disease will increase by $73 \%$ by 2030 in China (17). Chronic inflammation serves an important role in the occurrence and development of cardiovascular diseases (18). However, at present, the traditional anti-inflammatory therapies have not achieved satisfactory efficacy (19). Therefore, it is of significance to study the role and mechanism of the inflammatory reaction in cardiovascular disease. Full elucidation of the association between inflammation and cardiovascular disease in addition to exploring novel targets for intervention of vascular inflammation is important (19). In the present study, it was demonstrated that miR-214 downregulation inhibited cell proliferation and induced apoptosis in TNF- $\alpha$-induced vascular endothelial cells. Yang et al (20) has suggested that miR-214 inhibited left ventricular remodeling through suppressing cell apoptosis in acute myocardial infarction.

A large number of inflammatory markers and inflammatory mediators demonstrate the role of inflammatory responses in hypertensive disorders. In addition, innate and adaptive immune system disorders are important factors in the development of hypertension (21). In animal models with hypertensive diseases, the vessel wall is infiltrated by 
a large number of inflammatory cells. In addition, target organs including the heart and kidney are accompanied by varying degrees of inflammatory injury (22). Vascular inflammation is also involved in the pathophysiology of other hypertension-associated cardiovascular diseases, and vascular inflammation is suggested to be a bridge between hypertension and atherosclerosis (23). Specifically, it was observed that miR-214 downregulation increased TNF- $\alpha$, IL-1 $\beta$, IL-6 and IL-18 levels of TNF- $\alpha$ induces inflammation in vascular endothelial cells. Chen et al (24) demonstrated that the upregulated microRNA-214 enhances cardiac injury-induced inflammation. Future studies should investigate the role of miR-214 in vascular inflammation further by examining the effects of miR-214 overexpression in vascular endothelial cells.

PTEN expression is predominantly regulated by miRNA (miR-21), phosphorylation, acetylation and ubiquitination after transcription (15). A number of studies have demonstrated that the deletion of the PTEN gene serves an important role in the development and progression of tumors (25). In addition, its angiogenesis can be affected by PI3K/Akt signaling. The main process is that of PTEN reversing the phosphorylation of PI3K and removing the phosphatidylinositol-3 phosphate (PIP3) phosphate group through its lipid phosphatase activity. In this way, it is reduced to phosphatidylinositol-2-phosphate, maintaining low intracellular PIP3 levels $(25,26)$. At present, multiple experimental studies have reported that PTEN serves an important role in the regulation of key signals in tumor angiogenesis $(25,26)$. Notably, it was observed that miR-214 downregulation induced PTEN and NF- $\mathrm{B}$ protein expression and suppressed $\mathrm{p}$-Akt protein expression in TNF- $\alpha$-induced inflammation in vascular endothelial cells. Zhao et al (27) demonstrated that miR-214 promotes osteoclastogenesis by targeting the PTEN/PI3K/Akt pathway. Chu et al (28) reported that microRNA-214 suppresses NF- $\mathrm{B}$-mediated inflammatory responses in fish, further studies will aim to investigate this association anti-miR-214-mediated regulation of $\mathrm{NF}-\kappa \mathrm{B}$ in further detail.

PTEN additionally regulates the behavior of endothelial cells. Certain experiments have demonstrated that the PTEN expression is disrupted in most cell matrix and endothelial cells, thus reducing the activation of PTEN signaling in PI3K in endothelial cells (29). In addition, it leads to increased endothelial cell proliferation, survival and migration. These changes are often important factors and markers of tumor angiogenesis (29). It was additionally observed that the PTEN inhibitor inhibited the function of miR-214 on apoptosis and inflammation in TNF- $\alpha$-induced inflammation in vascular endothelial cells through PTEN/Akt signaling. Wang et al (30) suggested that microRNA-214 protects against hypoxia/reoxygenation-induced cell damage through suppression of PTEN and Bim1 expression. The present study lacked specificity of the PTEN inhibitor, future experiments should use siRNA to knockdown PTEN expression in order to investigate its role in miR-214-induced vascular inflammation.

In summary, the data of the present study demonstrated that the downregulation of miR-214 increased vascular inflammation and apoptosis via the PTEN/Akt signaling pathway in TNF- $\alpha$-induced inflammation in vascular endothelial cells Thus, miR-214 may serve a role in vascular inflammation and apoptosis that may be harnessed for use in clinical applications.

\section{Acknowledgements}

Not applicable.

\section{Funding}

No funding was received.

\section{Availability of data and materials}

The analyzed data sets generated during the study are available from the corresponding author on reasonable request.

\section{Authors' contributions}

MW designed the study and wrote the manuscript; ML, TN and QL performed the experiments; MW and ML analyzed the data.

\section{Ethics approval and consent to participate}

Not applicable.

\section{Consent for publication}

Not applicable.

\section{Competing interests}

The authors declare that they have no competing interests.

\section{References}

1. Mateos MV,Oriol A,Martínez-López J, Teruel AI, Bengoechea E, Palomera L, de Arriba F, Esseltine DL, Cakana A, Pei L, et al: Outcomes with two different schedules of bortezomib, melphalan, and prednisone (VMP) for previously untreated multiple myeloma: Matched pair analysis using long-term follow-up data from the phase 3 VISTA and PETHEMA/GEM05 trials. Ann Hematol 95: 2033-2041, 2016.

2. Liang J, Wang Y, Li H, Liu X, Qiu Q and Qi L: Neck circumference and early stage atherosclerosis: The cardiometabolic risk in Chinese (CRC) study. Cardiovasc Diabetol 13: 107, 2014.

3. Gómez-Pardo E, Fernández-Alvira JM, Vilanova M, Haro D, Martínez R, Carvajal I, Carral V, Rodríguez C, de Miguel M, Bodega $\mathrm{P}$, et al: A comprehensive lifestyle peer group-based intervention on cardiovascular risk factors: The randomized controlled fifty-fifty program. J Am Coll Cardiol 67: 476-485, 2016.

4. Chan DC, Pang J, McQuillan BM, Hung J, Beilby JP, Barrett PH and Watts GF: Plasma proprotein convertase subtilisin kexin type 9 as a predictor of carotid atherosclerosis in asymptomatic adults. Heart Lung Circ 25: 520-525, 2016.

5. Kobayashi R, Tamura K, Wakui H, Ohsawa M, Azushima K, Haku S, Uneda K, Ohki K, Haruhara K, Kinguchi S and Umemura S: Effect of single-pill irbesartan/amlodipine combination-based therapy on clinic and home blood pressure profiles in hypertension with chronic kidney diseases. Clin Exp Hypertens 38: 744-750, 2016.

6. Dissanayake E and Inoue Y: MicroRNAs in allergic disease. Curr Allergy Asthma Rep 16: 67, 2016.

7. Gao J, Ma X, Zhang Y, Guo M and Shi D: The role of microRNAs in prethrombotic status associated with coronary artery disease. Thromb Haemost 117: 429-436, 2017.

8. Orlicka-Płocka M, Gurda D, Fedoruk-Wyszomirska A, Smolarek I and Wyszko E: Circulating microRNAs in cardiovascular diseases. Acta Biochim Pol 63: 725-729, 2016. 
9. Ranković G, Milicić B, Savić T, Dindić B, Mancev Z and Pesić G: Effects of physical exercise on inflammatory parameters and risk for repeated acute coronary syndrome in patients with ischemic heart disease. Vojnosanit Pregl 66: 44-48, 2009.

10. Longenecker CT, Jiang Y, Yun CH, Debanne S, Funderburg NT, Lederman MM, Storer N, Labbato DE, Bezerra HG and McComsey GA: Perivascular fat, inflammation, and cardiovascular risk in HIV-infected patients on antiretroviral therapy. Int J Cardiol 168: 4039-4045, 2013

11. Sugimoto M, Ichio A and Kondo M: Short pulse duration high-power laser photocoagulation during vitrectomy for diabetic retinopathy reduces postoperative inflammation. PLoS One 10: e0135126, 2015.

12. García-Calzón S,Zalba G,Ruiz-Canela M, Shivappa N,Hébert JR, Martínez JA, Fitó M, Gómez-Gracia E, Martínez-González MA and Marti A: Dietary inflammatory index and telomere length in subjects with a high cardiovascular disease risk from the PREDIMED-NAVARRA study: Cross-sectional and longitudinal analyses over 5 y. Am J Clin Nutr 102: 897-904, 2015.

13. Ruiz-Canela M,ZazpeI,ShivappaN,HébertJR,Sánchez-Tainta A, Corella D, Salas-Salvadó J, Fitó M, Lamuela-Raventós RM, Rekondo J, et al: Dietary inflammatory index and anthropometric measures of obesity in a population sample at high cardiovascular risk from the PREDIMED (PREvención con DIeta MEDiterránea) trial. Br J Nutr 113: 984-995, 2015.

14. Lu C, Wang X, Ha T, Hu Y, Liu L, Zhang X, Yu H, Miao J, Kao R, Kalbfleisch J, et al: Attenuation of cardiac dysfunction and remodeling of myocardial infarction by microRNA-130a are mediated by suppression of PTEN and activation of PI3K dependent signaling. J Mol Cell Cardiol 89: 87-97, 2015.

15. Ling S, Birnbaum Y, Nanhwan MK, Thomas B, Bajaj M and Ye Y: MicroRNA-dependent cross-talk between VEGF and HIFlalpha in the diabetic retina. Cell Signal 25: 2840-2847, 2013.

16. Livak KJ and Schmittgen TD: Analysis of relative gene expression data using real-time quantitative PCR and the 2(-Delta Delta C(T)) method. Methods 25: 402-408, 2001

17. Zhou Y, Tian F, Wang J, Yang JJ, Zhang T, Jing J and Chen YD: Efficacy study of olmesartan medoxomil on coronary atherosclerosis progression and epicardial adipose tissue volume reduction in patients with coronary atherosclerosis detected by coronary computed tomography angiography: Study protocol for a randomized controlled trial. Trials 17: 10, 2016.

18. Jia P, Jin W, Teng J, Zhang H, Zou J, Liu Z, Shen B, Cao X and Ding X: Acute effects of hemodiafiltration versus conventional hemodialysis on endothelial function and inflammation: A randomized crossover study. Medicine (Baltimore) 95: e3440, 2016.

19. Neufcourt L, Assmann KE, Fezeu LK, Touvier M, Graffouillère L, Shivappa N, Hébert JR, Wirth MD, Hercberg S, Galan P, et al: Prospective association between the dietary inflammatory index and cardiovascular diseases in the SUpplémentation en VItamines et Minéraux AntioXydants (SU.VI.MAX) Cohort. J Am Heart Assoc 5: e002735, 2016.
20. Yang X, Qin Y, Shao S, Yu Y, Zhang C, Dong H, Lv G and Dong S: MicroRNA-214 inhibits left ventricular remodeling in an acute myocardial infarction rat model by suppressing cellular apoptosis via the phosphatase and tensin homolog (PTEN). Int Heart J 57: 247-250, 2016.

21. Riso P, Klimis-Zacas D, Del Bo' C, Martini D, Campolo J, Vendrame S, Møller P, Loft S, De Maria R and Porrini M: Effect of a wild blueberry (Vaccinium angustifolium) drink intervention on markers of oxidative stress, inflammation and endothelial function in humans with cardiovascular risk factors. Eur J Nutr 52: 949-961, 2013.

22. Reichert V, Xue X, Bartscherer D, Jacobsen D, Fardellone C, Folan P, Kohn N, Talwar A and Metz CN: A pilot study to examine the effects of smoking cessation on serum markers of inflammation in women at risk for cardiovascular disease. Chest 136: 212-219, 2009.

23. Høgh Kølbæk Kjær AS, Brinkmann CR, Dinarello CA, Olesen R, Østergaard L, Søgaard OS, Tolstrup M and Rasmussen TA: The histone deacetylase inhibitor panobinostat lowers biomarkers of cardiovascular risk and inflammation in HIV patients. AIDS 29: 1195-1200, 2015.

24. Chen ZG, Liu H, Zhang JB, Zhang SL, Zhao LH and Liang WQ: Upregulated microRNA-214 enhances cardiac injury by targeting ITCH during coxsackievirus infection. Mol Med Rep 12: 1258-1264, 2015.

25. Zhang QG, Wu DN, Han D and Zhang GY: Critical role of PTEN in the coupling between PI3K/Akt and JNK1/2 signaling in ischemic brain injury. FEBS Lett 581: 495-505, 2007.

26. Boosani CS and Agrawal DK: PTEN modulators: A patent review. Expert Opin Ther Pat 23: 569-580, 2013

27. Zhao C, Sun $\mathrm{W}$, Zhang $\mathrm{P}$, et al: miR-214 promotes osteoclastogenesis by targeting Pten/PI3k/Akt pathway. RNA Biol 12: 343-353, 2015.

28. Chu Q, Sun Y, Cui J and Xu T: Inducible microRNA-214 contributes to the suppression of NF-kappaB-mediated inflammatory response via targeting myd88 gene in fish. J Biol Chem 292: 5282-5290, 2017.

29. Kar S, Samii A and Bertalanffy H: PTEN/PI3K/Akt/VEGF signaling and the cross talk to KRIT1, CCM2, and PDCD10 proteins in cerebral cavernous malformations. Neurosurg Rev 38: 229-237, 2015

30. Wang X, Ha T, Hu Y, et al: MicroRNA-214 protects against hypoxia/reoxygenation induced cell damage and myocardial ischemia/reperfusion injury via suppression of PTEN and Bim1 expression. Oncotarget 7: 86926-86936, 2016. 